\title{
Nanoparticles: A Review of Preparation and Characterization of Nanoparticles with Application
}

\author{
Zaid Hamid Mahmoud, Noor Sabah Ahmed, Wafaa Shamkhi and Omar Dha'a \\ Department of Chemistry, College of Sciences, Diyala University, Iraq
}

\begin{abstract}
This review paper seeks into the present side of nanotechnology. It accords a compact painting of nanotechnology, preparing and its application in different fields such as solar cell, Robotics, medicine, computing and food technology etc. It is to transact with the future science of nanotechnology.
\end{abstract}

\section{Introduction}

Nanotechnology is the technology that deals with the particles that have at least one dimension in size $1-100 \mathrm{~nm}$. This means we manipulation of materials in tiny scale and this makes the materials have new surprising properties different from the same material in microsize such stronger, smaller, lighter and other more. It is a giveaway to develop the materials and inside it in many applications especially medicine. It should not be looked to this science just in size of particles, many applications started to use the science by doping it with bulk materials and giving excellent properties. The build and prepare nanoparticles based on two ways: first is from large materials and convert its small its called up to bottom and the second is build the nanoparticles from small particles its called bottom to up. We can classify the nanoparticles based on dimensions to one, two and three dimensions. One dimension that includes the film used in solar cell, catalyst and electronics applications. Two dimensions containing carbon nanotube that contains from a network of carbon atoms with $1 \mathrm{~nm}$ diameter and $100 \mathrm{~nm}$ length while, three dimensional is quantum dots that are device or particles with $2-10 \mathrm{~nm}$ diameter. In

Received: September 30, 2019; Accepted: December 29, 2019

Keywords and phrases: nanoelectronics, nanotubes, nanomedicine, nanofilms.

Copyright (C) 2020 Zaid Hamid Mahmoud et al. This is an open access article distributed under the Creative Commons Attribution License, which permits unrestricted use, distribution, and reproduction in any medium, provided the original work is properly cited. 
recent years, the nanotechnology has won private interest in the fields of nanotechnology and nanoscience due to the large surface area, economy, low cost and high efficiency [1$8]$.

\section{Preparation of nanoparticle}

The selected methods were used to prepare nanoparticles depend on the properties of a particle product such as oxides, nature product, drug and etc. In this review, we focused on the new method to prepare nanoparticles it called photolysis method and experimental parts.

\section{Photolysis method}

This method was used for the first time by Dr. Hussein Ismail and his student Zaid Hamid in MSC thesis study "synthesis of nanoferro oxide from it complexes and salts using photolysis method" in 2015 years. This method provides it successfully to prepare many phases of iron oxide: alpha, gamma and $\mathrm{Fe}_{3} \mathrm{O}_{4}$. The prepare steps depend on the medium of the solution, at the basic solution contains from one step while in the acidic or nature mediums contains from two steps. The first step is common that contains irradiation of salts or complex ferric ions with short time using the source of UV. During the irradiation the electron in the ground state of iron transfer from ground to excited state and this transition needs energy to jump electron to LUMO and it gets from UV irradiation and this cause reduction-oxidation reaction and conversion the oxidation state from 3 to 2 . If the irradiation occurred in basic medium, the hydroxyl ions attack on the iron ions in solution and make oxide directly while, when irradiated the starting materials in nature or acidic medium cause the major ions convert from +3 to +2 and product ferrous hydroxide. Then, it calcined using high temperature to product iron oxide nanoparticles. This method is bottom to up type. The system of irradiation was made manually by the two researchers as shown in Figure 2. It contains from the UV source with 125 watts. The power of watts plays major role in determining the time of irradiation. After that, this method was used by other researchers to prepare different oxide nanoparticles such as $\mathrm{TiO}_{2}, \mathrm{CuO}, \mathrm{Cr}_{2} \mathrm{O}_{3}, \mathrm{Ag}, \mathrm{Au}$ and other materials. These methods different from other like Sol-gel, co-precipitation, microwaves, ultrasonic, electric precipitation at the time, cost, size and don't energy. All these factors swing the photolysis method [9-22]. 


\section{Co-precipitation}

This method considers from oldest method to prepare the nanoparticles. It has an advantage and disadvantage, the advantage is the quantity of the particles are large, but the size of particles are different with a wide rang of size and the purity of the product is low. It includes adding wise drop basic materials such as ammonia or $\mathrm{NaOH}$ to salt solution to prepare precipitation of material hydroxide then, it calcined in $400 \mathrm{C}$ to prepare oxide [23].

\section{Sol-Gel}

The idea of this method based on preparing homogenous solution by using some chemical materials like citric acid. The mixing citric acid with salt make gel after adding the volume of $\mathrm{NaOH}$ with stirring until $\mathrm{pH}$ of solution become 7 . Then, calcined the product gel at $400 \mathrm{C}$. The method same the co-precipitation in disadvantage [25].

\section{Electrochemical precipitation}

These methods are same as the photolysis method in oxidation-reduction reaction, but differences in the base that causes the Redox reaction. These methods contain two electrodes, cathode and anode and choosing of electrode depends on the reduction potential and these connected with power supply and immersing in electrolyte solution. We can control the average of particles by controlling the power that supplied of reaction. The important point in this method is one of the electrodes must be the metal of the oxide that prepared.

\section{Extract method or green chemistry}

This method is the best of all methods in the side of green because do not need energy, prepare nanoparticles from cheap starting materials, purity and low average. This method is based on the reduction strength of the plant extract for metal ions in solution and converts it to less oxidation state formed metal hydroxide. After that, calcined the precipitate to product oxide nanoparticles.

\section{Uses of Nanotechnology}

We can use nanomaterials in many applications as follows: 


\section{Carbon Nano Tubes (CNT)}

Carbon nanotubes are allotropes of carbon having a cylindrical nanostructure. Nanotubes have been constructed with a length-to-diameter ratio of up to 2,80,00,000:1 that is much larger than any other material. These cylindrical carbon molecules possess extraordinary strength and unique electrical properties. These novel properties make them substantially useful in various applications in electronics, nanotechnology, optics, materials science, as well as in architectural fields. Their final usage, however, may be limited by their potential toxicity [26]. Nano tubes are shown in Figure 1.

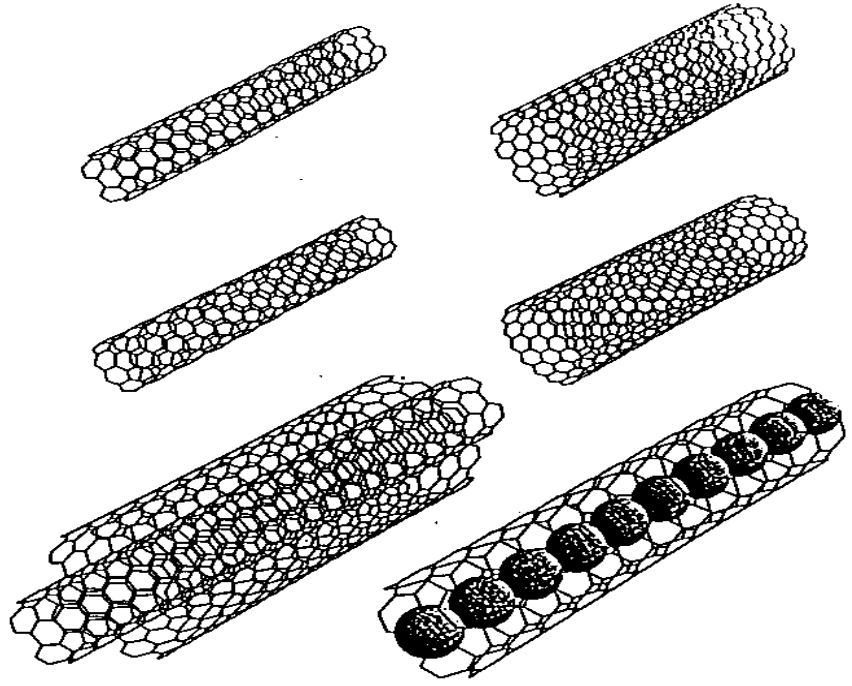

Figure 1. Carbon Nano Tubes (CNT).

\section{Thin Nano Films}

Various nanoscale materials can be used in thin films to make them water repellent, UV or IR-resistant, anti reflective, anti-microbial, self-cleaning, anti-fog, Scratch resistant or electrically conductive. Applications of Nano films include computer display, cameras and eyeglasses [26]. Nano film is shown in Figure 2. 


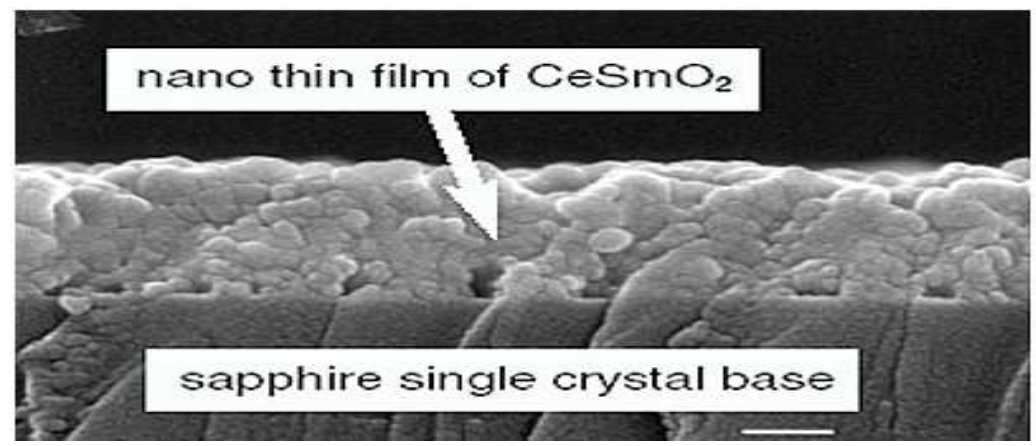

Figure 2. Thin Nano film [11].

\section{Nanoscale Transistors}

A transistor is a semiconductor electronic device used to amplify or switch electronic signals and electrical power. In transistors, a small amount of electricity is used as a gate to control the flow of larger amount of electricity. More the number of transistors are embedded in the computer, the greater will be power. Transistors sizes have been decreasing day by day, so computer have become more powerful. Up to now, the industry's best trading technology produced computer chips with transistors having 45nanometer features. Recent announcements indicate that even more small size of transistors is possible with the help of nanotechnology [26]. Nano scale transistors are shown in Figure 3.

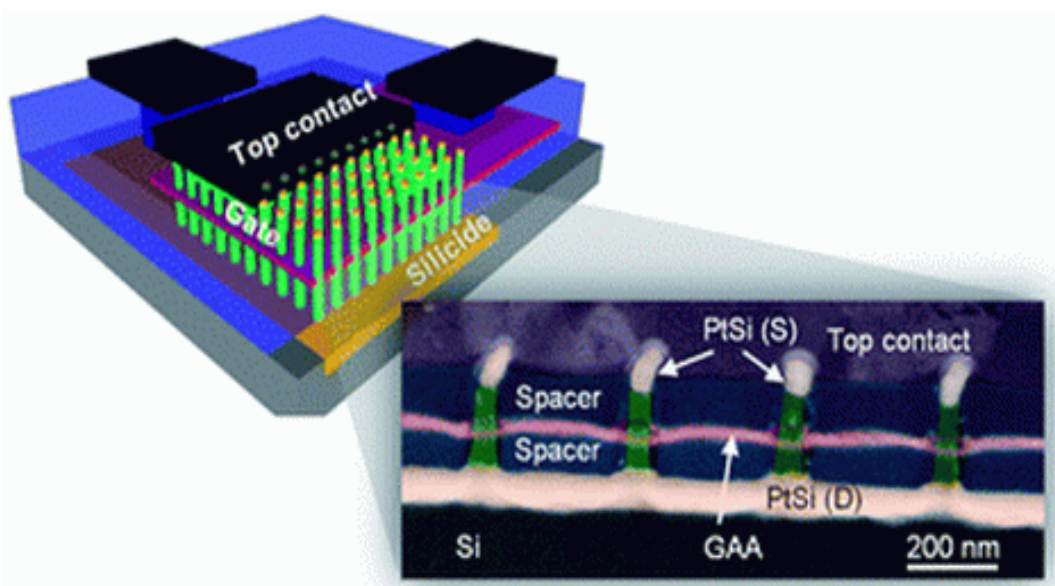

Figure 3. Nano scale transistors [12]. 


\section{Drug-Delivery Technique using Dendrimers}

Dendrimers are highly branched, star-shaped macromolecules with nanometer-scale dimensions shown in Figure 4. Dendrimers are specially designed and manufactured for a vast variety of applications, including the treatment of cancer, drug delivery, catalysis, gene transfixion, and energy harvesting and photo activity. Dendrimers carrying different materials and their branches can do several things at one time, such as perceiving diseased cells, diagnosing diseased states (including cell death), drug delivery, describing location and reporting events of therapy [26].
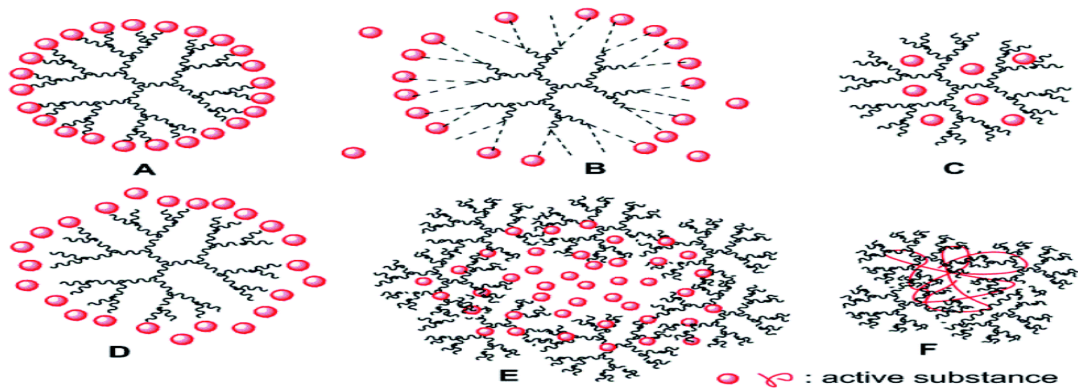

Figure 4. Drug delivery using dendrimers [Source 11].

\section{Water Filtration Technique}

Carbon nanotubes based membranes are used for water desalination and nanoscale sensors to diagnose contaminants in water system. The process of water filtration using carbon nanotubes is shown in Figure 5. Nanoscale titanium dioxide is the other nanoscale material that has great potential to filter and purify water system and it is also used in sunscreen to neutralize bacteria [26].

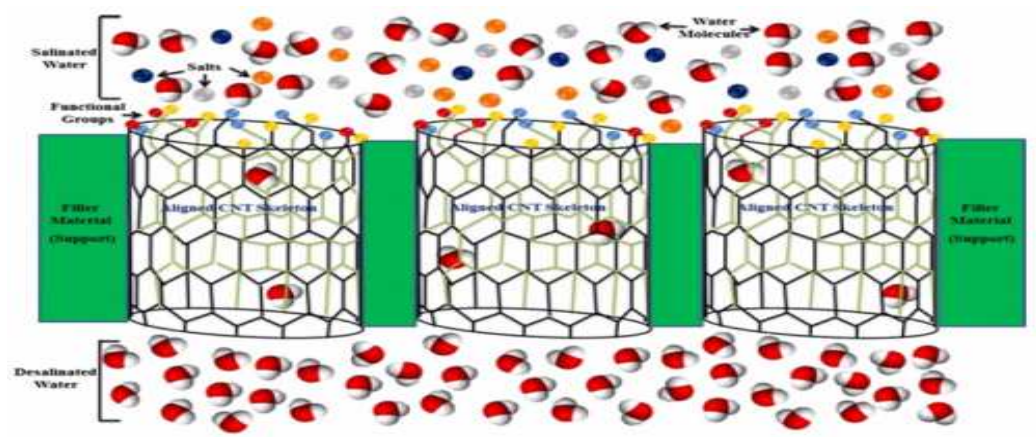

Figure 5. Water filtration technique [Source 8]. 


\section{Conclusion}

The science of nanotechnology deals with tiny particles. These particles have high effective because large surface area. Many methods were used to prepare nanoparticles but more of its give large agglomeration. Photolysis method is the best because low average particles and purity.

By the help of nanotechnology, doctors detecting disease at its earliest stages and treating illness such as heart disease, cancer and diabetes with more effective and safer medicines. Researchers also picture new technologies for protecting both the civilians and military forces of conventional and chemical weapons. Although there are many research challenges ahead, nanotechnology already is producing a vast range of favorable materials and pointing to developments in many fields. It has opened a scientific inquiry to the level of nanoparticles and gives a world of new opportunities.

\section{References}

[1] Handbook on Nanoscience, Engineering, and Technology, 2nd ed., Taylor and Francis, 2007.

[2] Centre Responsible for Nanotechnology, http://www.crnano.org/whatis.html

[3] Debnath Bhattacharyya, Shashank Singh, Niraj Satnalika, Ankesh Khandelwal and SeungHwan Jeon, Nanotechnology, big things from a tiny world: a review, International Journal of u- and e-Service, Science and Technology 2(3) (2009), 29-37.

[4] M. Ellin Doyle, Nanotechnology: A Brief Literature Review, FRI Briefings, 2006.

[5] Mark T. Lusk and L. D. Carr, Nanoengineering defect structures on grapheme, Physical Review Letters 100 (2008), 175503. https://doi.org/10.1103/PhysRevLett.100.175503

[6] Environment and Green Nano - Topics - Nanotechnology Project. Retrieved: 11 September 2011

[7] National Nanotechnology Initiative. http://www.nano.gov

[8] Nanotechnology in water treatment. Retrieved: 3 November 2013.

[9] H. M. Zaid, F. A. Nuha and A. A. Aklas, Effect of solvents on the size of copper oxide particles fabricated using photolysis method, Asian J. Chem. 30 (2018), 223-225. https://doi.org/10.14233/ajchem.2018.21047

[10] N. A. Ahmed and H. M. Zaid, Synthesis of $\alpha-\mathrm{Fe}_{2} \mathrm{O}_{3}$ nano powders by novel UV irradiation method, Diyala Journal for Pure Science 14 (2018), 57-67. http://dx.doi.org/10.24237/djps.1401.330B 
[11] A. F. Mohammed, H. M. Zaid and S. F. Marwa, Syntheses and characterization of $\mathrm{TiO}_{2} / \mathrm{Au}$ nanocomposite using UV-irradiation method and its photocatalytic activity to degradation of methylene blue, Asian J. Chem. 30 (2018), 1142-1146.

https://doi.org/10.14233/ajchem.2018.21256

[12] H. M. Zaid, The magnetic properties of alpha phase for iron oxide NPs that prepared from its salt by novel photolysis method, Journal of Chemical and Pharmaceutical Research 9(8) (2017), 29-33.

[13] H. M. Zaid, Effect of Au doping on the magnetic properties of $\mathrm{Fe}_{3} \mathrm{O}_{4}$ NPs prepared via photolysis and co-precipitation methods, Diyala Journal for Pure Science 14 (2018), 137147. http://dx.doi.org/10.24237/djps.1403.426A

[14] Zaid Hamid, Synthesis of bismuth oxide nano powders via electrolysis method and study the effect of change voltage on the size for it, Aust. J. Basic \& Appl. Sci. 11(7) (2017), 97101.

[15] Z. H. Mahmoud and R. F. Khudeer, Spectroscopy and structural study of oxidative degradation Congo Red Dye under sunlight using $\mathrm{TiO}_{2} / \mathrm{Cr}_{2} \mathrm{O}_{3}$-CdS nanocomposite, International Journal of ChemTech Research 12(3) (2019), 64-71.

https://doi.org/10.20902/IJCTR.2019.120311

[16] Zaid Hamid Mahmoud, Marwa Sabbar Falih, Omaima Emad Khalaf, Mohammed Alwan Farhan and Farah Kefah Ali, Photosynthesis of $\mathrm{AgBr}$ Doping $\mathrm{TiO}_{2}$ Nanoparticles and degradation of reactive red 120 dye, J. Adv. Pharm. Edu. Res. 8(4) (2018), 51-55.

[17] Zaid Hamid Mahmoud, Marwah Hashim and Farah Kefah Ali, Low temperature photosynthesis of $\mathrm{Bi}_{2} \mathrm{O}_{3}$ nano powder, Earthline Journal of Chemical Sciences 2(2) (2019), 303-307. https://doi.org/10.34198/ejcs.2219.303307

[18] Nuha Abdul Jaleel Omran, Zaid Hamid Mahmoud, Noor Kadhum Ahmed and Farah Kefah Ali, Low-temperature synthesis of $\alpha-\mathrm{Fe}_{2} \mathrm{O}_{3} / \mathrm{MWCNTS}$ as photo-catalyst for degradation of organic pollutants, Orient J. Chem. 35(1) (2019), 332-336. https://doi.org/10.13005/ojc/350140

[19] Wijdan Amer Ibrahim and Zaid Hamid Mahmoud, Synthesis and characterization of new Fe-complex and its nanoparticle oxide using the novel photolysis method, International Journal of Pharmaceutical and Phytopharmacological Research 8 (2018), 57-61.

[20] Noor Sabah Al-Obaidi, Zaid Hamid Mahmoud, Ahlam Ahmed Frayyih Anfal S. Ali and Farah K. Ali, Evaluating the electric properties of poly aniline with doping $\mathrm{ZnO}$ and $\alpha$ Fe2O3 nanoparticles, Pharmacophore 9(5) (2018), 61-67 
[21] Zaid Hamid Mahmoud, Omaima Emad Khalaf and Mohammed Alwan Farhan, Novel photosynthesis of $\mathrm{CeO}_{2}$ nanoparticles from its salt with structural and spectral study, Egyptian Journal of Chemistry 62(1) (2019), 141-148.

[22] Zaid Hamid Mahmoud and Aklas Ahmed Abdalkareem, Removal of $\mathrm{Pb}^{+2}$ ions from water by magnetic iron oxide nanoparticles that prepared via ECD, European Journal of Scientific Research 145(4) (2017), 354-365.

[23] http://faculty.tamu-commerce.edu/dyeager/599/newtechnologyparti_files/ v3_slide0205.htm Contemporary Tech

[24] William Illsey Atkinson, Nanocosm: Nanotechnology and the Big Changes Coming from the Inconceivably Small, New York: AMACOM, 2003. https://www.questia.com/read/118926256/nanocosm-nanotechnology-and-the-big-changes-coming

[25] http://www.nottingham.ac.uk/physics/research/nano/pdfs/N15ND05.pdf Nanotechnology.

[26] Nanoelectronics: Nanotechnology in Electronics. http://www.understandingnano.com 